Research Article

\title{
Coupling Ratio-Based Design and Seismic Performance of Modular Prefabricated Hybrid Coupled Walls
}

\author{
Yun Shi $\mathbb{1}$, Yumin Zhang, Jianbo Dai, and Guangyuan Weng \\ Department of Civil Engineering, Xi'an Shiyou University, Xi'an, China \\ Correspondence should be addressed to Yun Shi; shiyun0305@163.com
}

Received 14 February 2019; Revised 19 April 2019; Accepted 24 April 2019; Published 20 May 2019

Academic Editor: Constantin Chalioris

Copyright (C) 2019 Yun Shi et al. This is an open access article distributed under the Creative Commons Attribution License, which permits unrestricted use, distribution, and reproduction in any medium, provided the original work is properly cited.

\begin{abstract}
Based on the advantages of modular prefabricated multistory steel structure, a full-bolt-connected modular steel coupling beam-hybrid coupled wall system is presented. Further, a method of estimating the coupling ratio (CR) is proposed according to the continuous link method. A CR-based seismic design procedure is determined such that the structure utilizes the lateral stiffness of the shear wall, which is necessary to avoid structural damage under frequently occurring earthquakes. However, it also exhibits excellent ductility of the coupling beams, which is necessary for dissipating energy under infrequent earthquakes. Subsequently, nonlinear hysteretic analyses are conducted from finite element analysis software ABAQUS, and a parametric study based on the finite element technique is performed to identify the optimal value of the coupling ratio. Results indicate that the seismic performance of modular prefabricated HCWs was excellent, and the basic requirements for ductile behavior and lateral stiffness were satisfied for CR values from $50 \%$ to $60 \%$. The obtained results confirm the accuracy of the CR-based seismic design method proposed in this study and are supported by the selection of the design parameter at the initial design stage.
\end{abstract}

\section{Introduction}

Reinforced concrete (RC) walls are an important lateral force-resisting component, even if they might suffer from unexpected shear failure under earthquakes [1]. Steelreinforced concrete (SRC) shear walls with steel boundary elements were used to improve the seismic performance of shear walls, which is a typical structure used in high-rise and super high-rise buildings. In practical projects, the design and construction methods on these structures have matured and evolved [2-4]. However, owing to functional requirements and architectural design needs, when forming a coupled wall system using conventional RC coupling beams, two types of problems have been exhibited: first, a distinct brittle shear failure often occurs in the RC coupling beams because of the relative smaller spanheight ratio; second, conventional RC coupling beams suffer from being difficult to connect with steel boundary elements when under construction and are difficult to repair after seismic damage. Steel coupling beams are a more desirable alternative, because of their more stable hysteretic behavior (such as in eccentrically braced frames) and easy construction methods if the connection between steel beams and steel boundary elements are welded [5-7], as shown in Figure 1.

This structural system has been defined as the hybrid coupled wall (HCW) system. However, some experimental investigations indicated that field-welding quality is difficult to control in key parts of the connection, and unexpected brittle failure has often been observed between the weld metal and base metal at the toe of the weld access holes $[8,9]$. Therefore, to improve the assemblability of SRC shear walls with steel boundary elements and steel coupling beams, referring to the advantages of modular prefabricated multistory steel structures [10-17], an innovative modular prefabricated HCW system is presented in this study. This modular prefabricated HCW system is composed of two SRC walls with steel boundary elements coupled using a full-bolt-connected modular steel coupling beam, and the modules can be assembled rapidly without 


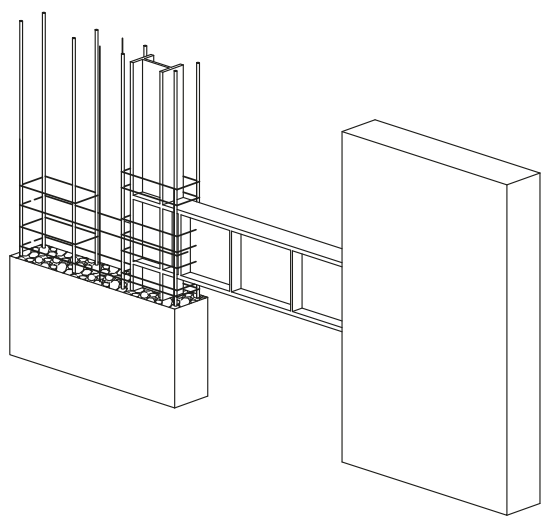

Figure 1: Sketch of the HCW system with connection welded.

being welded on site. The proposed connection consists of a column base with vertical connecting plate, an upper column with cover plate flange, a lower column with cover plate flange, a flitch plate, and a steel coupling beam, as shown in Figure 2. Each module is welded separately at the factory, and the two adjacent modules are bolted on the construction site, such that all modules are connected together. A full-bolt connection used in the proposed innovative system is more convenient, and damaged steel coupling beams can be replaced after earthquakes. Brittle failure owing to poor welded quality is avoided, as long as the appropriate connection detailing is used, which is analyzed and detailed in the literature [18]. The existing research focuses primarily on the construction methods and hysteretic behavior for the modular prefabricated connection.

In this study, the focus is on the coupling ratio of the structure and the seismic design procedure for the modular prefabricated HCW system under earthquakes. Specifically, a method for estimating the coupling ratio (CR) is proposed (according to the continuous link method), and a CR-based seismic design procedure is deduced for achieving satisfactory seismic performance, meaning the coupling beam yields before damage occurs in the shear wall. Based on the results of this new design method, the seismic performance of models with different CRs is analyzed under hysteretic pushover analyses to determine a suitable value for the coupling ratio.

\section{Coupling Ratio of the Modular Prefabricated HCWs}

2.1. Definition of Coupling Ratio. Base reactions under horizontal loads in the modular prefabricated HCW system are shown in Figure 3. The CR is defined as the proportion of the moment resisted by two shear walls $(N \times L)$ in the total resisted moment $(V \times H)$. The CR characterizes the behavior of the coupled system, meaning it quantifies the contribution provided by the coupling action in resisting horizontal forces [19]; as such, it is an important design parameter as it allows tailoring the respective roles of the shear walls and steel coupling beams in the resisting mechanism. It can be calculated as follows:

$$
\mathrm{CR}=\frac{N \times L}{V_{1} \times H_{1}},
$$

where $N$ is the axial force resisted by the shear wall $\left(N_{1}=N_{2}=N\right), L$ is the axis length of the modular prefabricated HCW system, $V_{1}$ is the horizontal shear force resisted by the system, and $H_{1}$ is the height of the horizontal load.

\subsection{Estimation of $C R$}

2.2.1. Hypothesis of the Continuous Link Method. According to the continuous link method, the coupling beams are equivalent to a type of continuous link with uniform distribution along the height of the building. The basic structure is shown in Figure 4, and the following hypotheses are adopted:

(i) The section dimensions of the walls and coupling beams remain unchanged along the height of the building

(ii) The section dimensions of two walls are equal

(iii) The plane section assumption is satisfied

(iv) The axial stiffness of the coupling beam is infinite

\subsubsection{Establishment of Differential Equations}

(1) Vertical displacement of coupling beam incisions caused by bending deformation of shear walls is as follows:

$$
\delta_{1 \mathrm{M}}=L \cdot \frac{d y}{d x}
$$

where $d y / d x$ is the slope of the shear wall centroid axis.

The shear deformation of the wall will not cause a relative displacement of coupling beam incisions. Thus,

$$
\begin{aligned}
& \delta_{1 \mathrm{~V}}=0, \\
& \delta_{1}=\delta_{1 \mathrm{~V}}+\delta_{1 \mathrm{M}}=L \cdot \frac{d y}{d x}
\end{aligned}
$$

(2) Vertical displacement of the coupling beam incisions caused by axial deformation of shear walls is as follows:

$$
\delta_{2}=\frac{1}{E_{\mathrm{c}}}\left(\frac{1}{A_{1}}+\frac{1}{A_{2}}\right) \int_{0}^{x} \tau(x) d x,
$$

where $E_{\mathrm{c}}$ is the elastic modulus of concrete (ignore the influence of the steel boundary elements); $A_{1}=A_{2}=A_{\mathrm{w}}$ is the cross-sectional area of the shear wall; and $\tau(x)$ is the shear force flow at incision of coupling beams.

(3) Vertical displacement of coupling beam incisions caused by bending and shear deformation of coupling beams is as follows: 


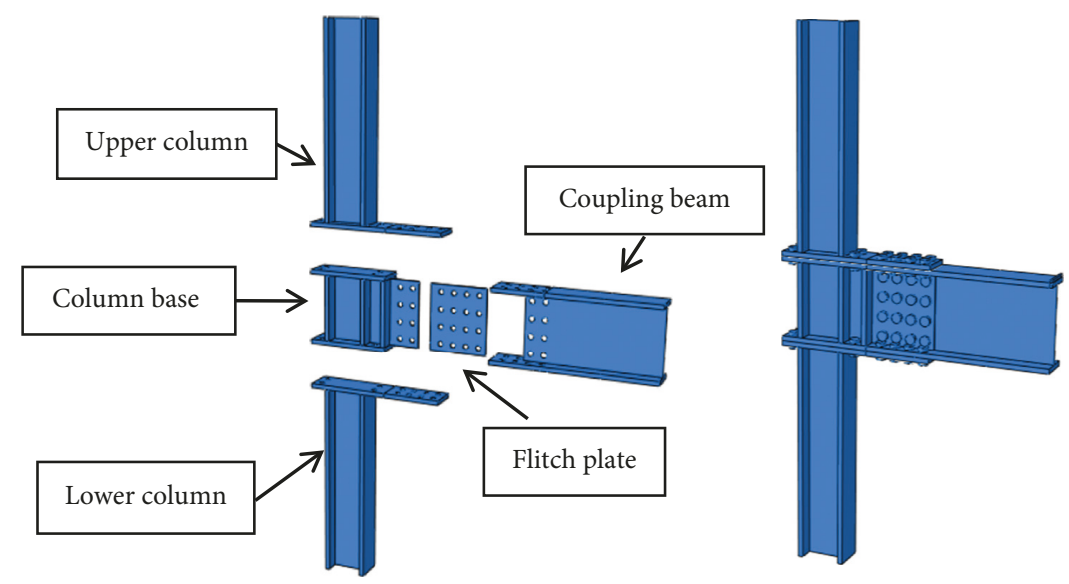

(a)

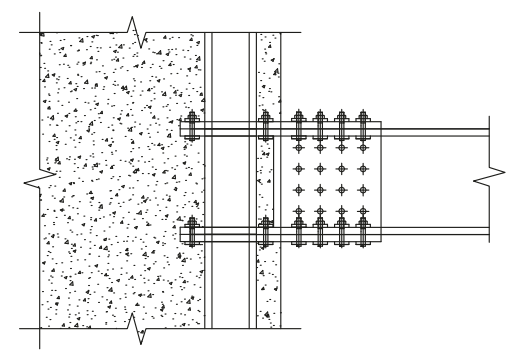

(b)

Figure 2: Sketch of the modular prefabricated HCW system. (a) Structural diagram of the connection. (b) Details of the connection.

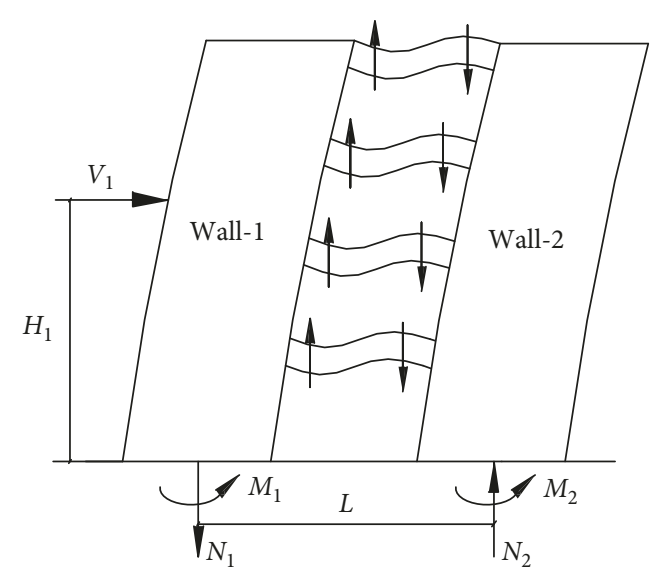

Figure 3: Base reactions under horizontal loads.

$$
\begin{aligned}
\delta_{3 \mathrm{M}} & =\frac{2 \tau(x) h a^{3}}{3 E_{\mathrm{s}} I_{\mathrm{b}}} \\
\delta_{3 \mathrm{~V}} & =2 \int_{0}^{a} \gamma d y=2 \int_{0}^{a} \frac{\mu \tau(x) h}{G_{\mathrm{s}} A_{\mathrm{b}}} d y=\frac{2 \mu \tau(x) h a}{G_{\mathrm{s}} A_{\mathrm{b}}} \\
\delta_{3} & =\delta_{3 \mathrm{M}}+\delta_{3 \mathrm{~V}}=\frac{2 \tau(x) h a^{3}}{3 E_{\mathrm{s}} A_{\mathrm{b}}}\left(1+\frac{3 \mu E_{\mathrm{s}} I_{\mathrm{b}}}{A_{\mathrm{b}} G_{\mathrm{s}} a^{2}}\right) .
\end{aligned}
$$

If

$$
\widetilde{I}_{\mathrm{b}}=\frac{I_{\mathrm{b}}}{1+\left(3 \mu E_{\mathrm{s}} I_{\mathrm{b}} / A_{\mathrm{b}} G_{\mathrm{s}} a^{2}\right)},
$$

subsequently, $\delta_{3}$ is computed as follows:

$$
\delta_{3}==\frac{2 \tau(x) h a^{3}}{3 E_{\mathrm{s}} \widetilde{I}_{\mathrm{b}}}
$$

where $I_{\mathrm{b}}$ is the inertia moment of the coupling beams, $\widetilde{I}_{\mathrm{b}}$ is the calculating equivalent inertia moment of the coupling beams considering the shear deformation, $a$ is the $1 / 2$ span of the coupling beams, $h$ is the height of the floor, $\mu$ is the uniformity distributed factor of the shear stresses in the

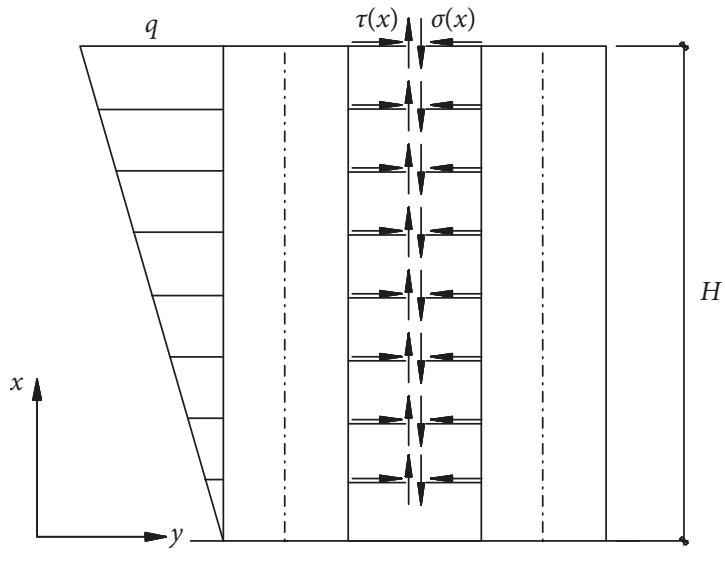

Figure 4: Base structure.

coupling beam, $G_{\mathrm{s}}$ is the shear modulus of steel, and $A_{\mathrm{b}}$ is the cross-sectional area of the coupling beams.

The relative displacement is zero at the coupling beam incisions. Thus,

$$
\begin{aligned}
\delta=\delta_{1}+\delta_{2}+\delta_{3}= & L \cdot \frac{d y}{d x}-\frac{2}{E_{\mathrm{c}} A_{\mathrm{w}}} \\
& \cdot \int_{0}^{a} \tau(x) d x-\frac{2 \tau(x) h a^{3}}{3 E_{\mathrm{s}} \widetilde{I}_{b}}=0 .
\end{aligned}
$$

The curvature at any point on the curve $y=f(x)$ can be approximated as follows:

$$
\frac{1}{\rho}=\frac{-d^{2} y}{d x^{2}} .
$$

The relationship between bending moment and curvature in the shear wall is derived as follows:

$$
E_{\mathrm{c}}\left(I_{1}+I_{2}\right) \frac{d^{2} y}{d x^{2}}=M_{1}+M_{2}
$$

where $I_{1}=I_{2}=I_{\mathrm{w}}$ is the inertia moment of the shear walls.

The equilibrium condition of the system is calculated as follows: 


$$
M_{1}+M_{2}=M(x)-L N(x)
$$

where

$$
\tau(x)=-\frac{d N}{d x} .
$$

Solving the simultaneous equations (8)-(12), the following equation is obtained:

$$
\frac{d^{2} N}{d x^{2}}-(k \alpha)^{2} N(x)=-\frac{\alpha^{2}}{L} M(x),
$$

where

$$
\begin{aligned}
\alpha^{2} & =\frac{3 E_{\mathrm{s}} L^{2} \cdot \widetilde{I}_{\mathrm{b}}}{2 E_{\mathrm{c}} a^{3} h I_{\mathrm{w}}}, \\
k^{2} & =1+\frac{4 I_{\mathrm{w}}}{A_{\mathrm{w}} L^{2}} .
\end{aligned}
$$

The solution of the equation consists of two parts: a general solution and special solution:

$$
\begin{aligned}
N_{c}(x)= & C_{1} \cosh k \alpha(H-x)+C_{2} \sinh k \alpha(H-x) \\
& +\left(1+\frac{D^{2}}{(k \alpha)^{2}}+\frac{D^{4}}{(k \alpha)^{4}}+\cdots\right) \frac{M(x)}{L k^{2}} .
\end{aligned}
$$

According to the equivalent base shear method, the horizontal force distribution is assumed as an inverted triangle, and the bending moment at the $x$ cross section under horizontal load is calculated as follows:

$$
M(x)=\frac{q(H-x)^{2}}{2}-\frac{q(H-x)^{3}}{6 H} .
$$

Using the boundary conditions:

(i) $x=H, N=0$

(ii) $x=0, d N / d x=0$

$$
\begin{aligned}
N_{c}= & \frac{q H^{2}}{k^{2} L}\left\{\frac{[\sinh k \alpha H-(k \alpha H / 2)+(1 / k \alpha H)]}{(k \alpha H)^{2} \cosh k \alpha H}\right. \\
& \cdot \sinh k \alpha(H-x)-\frac{1}{(k \alpha H)^{2}} \cosh k \alpha(H-x) \\
& \left.+\frac{1}{2}\left(1-\frac{x}{H}\right)^{2}-\frac{1}{6}\left(1-\frac{x}{H}\right)^{3}+\frac{1}{(k \alpha H)^{2}}\left(\frac{x}{H}\right)\right\},
\end{aligned}
$$

and setting $x=0$, the axial force at the bottom of the shear wall is given as follows:

$$
\begin{aligned}
N_{c}= & \frac{q H^{2}}{k^{2} L}\left\{\frac{[\sinh k \alpha H-(k \alpha H / 2)+(1 / k \alpha H)]}{(k \alpha H)^{2} \cosh k \alpha H}\right. \\
& \left.\cdot \sinh k \alpha H-\frac{\cosh k \alpha H}{(k \alpha H)^{2}}+\frac{1}{3}\right\} .
\end{aligned}
$$

The bending moment at the bottom of the structure under the horizontal load is calculated as follows:

$$
M=\frac{q H^{2}}{3} .
$$

The CR is calculated as follows:

$$
\mathrm{CR}=\frac{N_{\mathrm{c}} L}{M} .
$$

Solving equations (19)-(21) simultaneously, the following equation is obtained:

$$
\begin{aligned}
C R= & \frac{3}{k^{2}(k \alpha H)^{2}}\left[\frac{(k \alpha H)^{2}}{3}-\cosh (k \alpha H)\right. \\
& \left.+\sinh (k \alpha H) \times \frac{\sinh (k \alpha H)-(k \alpha H / 2)+(1 / k \alpha H)}{\cosh (k \alpha H)}\right],
\end{aligned}
$$

where $k$ is calculated by formula (15) and $\alpha$ is calculated by formula (14).

\section{CR-Based Design of the Modular Prefabricated HCW System}

3.1. Basic Design Methodology of the Modular Prefabricated HCW System. In the seismic design process, it is important to be aware of setting multiple seismic lines of defense. For the modular prefabricated HCW system, coupling beams with excellent energy dissipation were used as the first seismic line of protection, avoiding unnecessary economic losses, injury, and death. With a rational performance-based design, the structure permits utilizing the lateral stiffness of the shear wall, which is necessary for avoiding structural damage under frequently occurring earthquakes. However, it also exhibits excellent ductility of the coupling beams, which is necessary for dissipating energy under infrequent earthquakes [20]. It has been proven that the CR value affects the appearance sequence of the hinge directly. Hence, the CR should be used as an essential parameter where the cross section of the structural elements has been initially determined. To achieve our desired performance objective, the flow chart of this iterative method is shown in Figure 5.

3.2. Design of Shear Wall Dimensions. The dimensions of the shear wall are chosen by selecting the minimum value of the width $b_{\mathrm{w}}$ to provide adequate shear strength. For example, the maximum value of $h / b_{\mathrm{w}}$ is equal to 16 and $b_{\mathrm{w}}$ should not be less than $160 \mathrm{~mm}$ for the first seismic grade, which is recommended in GB50011-2010 [21]. Further, based on JGJ3-2010, the suggested minimum value for the height-tolength $\left(H / l_{\mathrm{w}}\right)$ ratio is three. The slender shear walls can be bent, enabling plastic deformation in the coupling beams.

3.3. Deciding an Initial Value of the CR. To understand the influence of the CR on seismic performance, and to determine the most suitable CR requirement of the structure, the CR value is varied from $40 \%$ to $70 \%$. In this study, various values of the $\mathrm{CR}$ are achieved by changing the cross section of the coupling beams. 


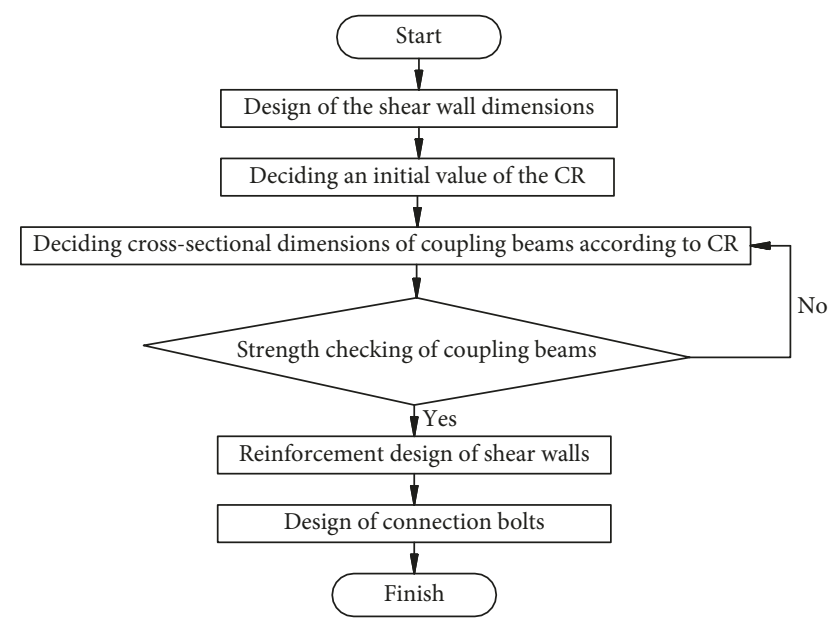

FIgURE 5: Flow chart of design method.

3.4. Deciding Cross-Sectional Dimensions of Coupling Beams according to $C R$. According to equation (22), once the CR is chosen, the initial cross-sectional dimensions of the coupling beams can be derived.

3.5. Bearing Capacity Checking of Coupling Beams. The horizontal load $V$ acting on the structure can be calculated by the equivalent base shear method. According to equation (1), the shear force resisted by the coupling beam can be obtained as follows:

$$
V_{\text {beam }, i}=\frac{\mathrm{CR} \times V \times H_{1}}{n L},
$$

and the bending moment in the coupling beam can be obtained as follows:

$$
M_{\text {beam }, i}=2 a V_{\text {beam }, i} .
$$

According to JGJ99-2015 [17], the plastic shear and bending bearing capacity should satisfy the following equations:

$$
\begin{aligned}
& V_{\mathrm{p}}=0.58 f_{\mathrm{y}} h_{0} t_{\mathrm{w}} \geq V_{\text {beam }, i}, \\
& M_{\mathrm{p}}=f_{\mathrm{y}} b_{\mathrm{f}} t_{\mathrm{f}}\left(h_{0}+t_{f}\right) \geq M_{\text {beam }, i},
\end{aligned}
$$

where $h_{0}$ is the web depth, $t_{\mathrm{w}}$ is the web thickness, $t_{\mathrm{f}}$ is the flange thickness, $b_{\mathrm{f}}$ is the flange width, and $f_{\mathrm{y}}$ is the yield strength of steel.

In this step, if equation (9) or (10) is invalid, alternative cross sections of the coupling beams should be decided again, according to the CR.

\subsection{Reinforcement and Steel Boundary Elements in the Design} of Shear Walls. The moment resisted by the two shear walls can be obtained from the shear force by coupling beams $V_{\text {beam }}$ and $\mathrm{CR}$ as follows:

$$
M_{\mathrm{w}}=\frac{1}{2}\left(\frac{\sum_{1}^{n} V_{\text {beam }} L}{\mathrm{CR}}-\sum_{1}^{n} V_{\text {beam }} L\right) .
$$

The base shear force resisted by the two shear walls can be obtained from the horizontal load as follows:

$$
V_{\mathrm{w}}=\frac{1}{2} V
$$

The axis force resisted by the two shear walls can be obtained from the shear force by coupling beams $V_{\text {beam }}$ as follows:

$$
N_{\mathrm{w}}=\sum_{1}^{n} V_{\text {beam }, i}
$$

"Strong shear and weak bending" is an important design concept. Meanwhile, to fully estimate the bending moment and shear force at the bottom of the shear wall, and to satisfy the sequence of plastic hinge development, the bending moment at the base of the shear wall is $M_{\mathrm{w}}, d=1.1 M_{\mathrm{w}}$, and the base shear force is $V_{\mathrm{w}}, d=1.3 V_{\mathrm{w}}$. Consequently, the bending moment design value $M_{\mathrm{w}}$, $d$ used to calculate the section of steel boundary elements and longitudinal reinforcements is $1.1 M_{\mathrm{w}}$. Further, the shear force design value $V_{\mathrm{w}}, d$ used to calculate the section of transverse reinforcements is $1.3 V_{\mathrm{w}}$. The detailed design method of an SRC shear wall with steel boundary elements can be referred to in JGJ138-2016 [22].

3.7. Design of Connection Bolts. The connection calculation assumes that the bolted connections are subjected to the whole external force on the coupling beam. The bolts on the flanges bear all of the bending moment, whereas the bolts on the web plate bear all of the shear force. Previous studies have shown that prying action by the cover plate on the flange surface is extremely small [23]; therefore, it is neglected in the calculation. The design shear capacity of one bolt is given by the following equation [22]:

$$
N_{\mathrm{v}}^{\mathrm{b}}=n_{\mathrm{f}} \mu p \text {. }
$$

The web bolts with shearing capacity should satisfy the following equation:

$$
V=n_{1} N_{\mathrm{v}}^{\mathrm{b}} \geq V_{\mathrm{p}}
$$

The flange bolts with bending capacity should satisfy the following equation:

$$
M=n_{2} N_{\mathrm{v}}^{\mathrm{b}} \cdot h_{\mathrm{b}} \geq M_{\mathrm{p}}
$$

where $n_{\mathrm{f}}$ is the number of friction surfaces, $\mu$ is the friction coefficient, $p$ is the design value of pretension, $h_{\mathrm{b}}$ is the depth of coupling beam, and $n_{1}$ and $n_{2}$ are the numbers of web bolts and flange bolts, respectively.

\section{Application to the CR-Based Seismic Design of the Modular Prefabricated HCWs}

4.1. Description of Case Study. The modular prefabricated HCWs are modeled as a portion of a 12-story residential building in a seismic zone. The adopted positions of the modular prefabricated HCW system in the building are shown in Figure 6. In order to simplify the analysis procedures, the effect of boundary columns is neglected, and shear walls are considered to bear in-plane loads only. The design axial compression ratio is regarded as 0.2 , and the 


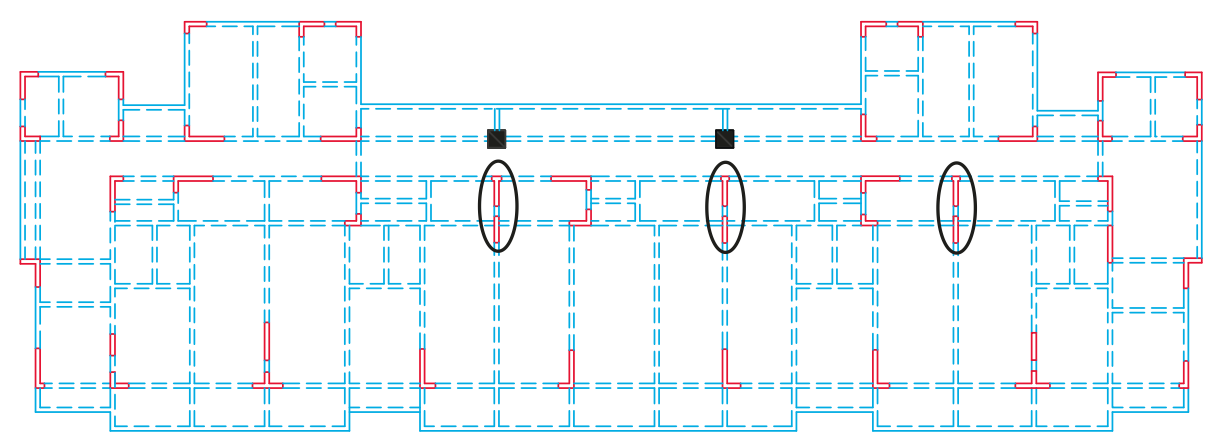

Figure 6: Plan view of the structure.

seismic design loads were estimated according to GB500112010 [21]. The designs are characterized by a peak ground acceleration of $0.3 \mathrm{~g}$ with $10 \%$ probability of exceedance in a 50 -year period and moderately firm ground conditions. The design procedure of the HCWs is consistent with that in Section 3, and the following is detailed explanation. Four modular prefabricated HCW prototypes with four different values of CR $(40 \%, 50 \%, 60 \%$, and $70 \%)$ were designed, which are termed CR-40, CR-50, CR-60, and CR-70, respectively. In all designs, the story height is $2.8 \mathrm{~m}$. The coupling beams and steel boundary elements of the structures used steel Q345B with a nominal yield strength of $345 \mathrm{MPa}$ and the reinforcement used HRB335 with a nominal yield strength of $335 \mathrm{MPa}$, while the shear walls used C30 concrete with a cylindrical compressive strength of $30 \mathrm{MPa}$.

4.2. Designs. The first step is to determine the geometry of the shear wall that results in a wall length $\left(l_{\mathrm{w}}\right)=2.5 \mathrm{~m}$, $b_{\mathrm{w}}=0.25 \mathrm{~m}$, and $H$ being equivalent to $33.6 \mathrm{~m}$, which is in accordance with the minimum height-to-length ratio.

The second step is deciding the cross section of the coupling beams according to the CR (40\%, 50\%, $60 \%$, or $70 \%)$ and verification of the bearing capacity of the coupling beams. An initial cross section of the coupling beam must be selected according to equation (22) and subsequently verified to be compatible with the bearing capacity requirement. The design of the coupling beams must satisfy equations (25) and (26), such that the bending capacity is greater than the design moment value, and the shear capacity is greater than the design shear value. In addition, the coupling beams should be designed as shear yielding as far as possible according to JGJ99-2015. The coupling beam sections and length are summarized in Table 1.

The third step is designing the reinforcement and steel boundary elements of the shear walls. Having evaluated the bending moment, base shear, and axis force based on equations (9)-(11), the bending moment, base shear, and axis force of the shear wall are evaluated. The same steel boundary element section is utilized to all stories to satisfy the hypothesis of the continuous link in Section 2.2. A detailed drawing of the shear wall is illustrated in Figure 7. Both the horizontal and vertical distributing reinforcement are.10@200.

The final step is designing the connection bolts. Here, Grade S10.9 M24 bolts are used in model CR-60, four bolts
Table 1: Properties of coupling beam.

\begin{tabular}{lcccc}
\hline $\begin{array}{l}\text { Model } \\
\text { name }\end{array}$ & $\begin{array}{c}\text { Length } \\
(\mathrm{mm})\end{array}$ & Section & $\begin{array}{c}M_{\mathrm{p}} \\
(\mathrm{kN} \cdot \mathrm{m})\end{array}$ & $\begin{array}{c}V_{\mathrm{p}} \\
(\mathrm{kN})\end{array}$ \\
\hline CR-40 & 1000 & $\mathrm{H} 200 \times 100 \times 3 \times 10$ & 59.9 & 98.7 \\
CR-50 & 1000 & $\mathrm{H} 250 \times 150 \times 4 \times 10$ & 113.4 & 168.1 \\
CR-60 & 1000 & $\mathrm{H} 310 \times 150 \times 8 \times 20$ & 274.1 & 394.6 \\
CR-70 & 1000 & $\mathrm{H} 560 \times 220 \times 10 \times 20$ & 748.4 & 950.0 \\
\hline
\end{tabular}

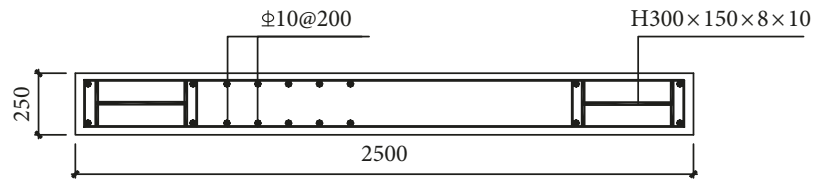

Figure 7: Detailed drawing of shear wall.

are arranged on each flange member, and eight bolts are arranged on the web member. The slip coefficient of highstrength bolts prepared by hardwire brushing is 0.5 [24]. The design shear capacity of one M24 bolt is given as follows:

$$
N_{\mathrm{v}}^{\mathrm{b}}=n_{\mathrm{f}} \mu p=1 \times 0.5 \times 225=112.5 \mathrm{kN} \text {. }
$$

The bending capacity at the end of the coupling beam supported by the flange bolts is as follows:

$$
M=n_{2} N_{\mathrm{v}}^{\mathrm{b}} \cdot h_{\mathrm{b}}=8 \times 112.5 \times 310=279.0 \mathrm{kN} \cdot \mathrm{m} \geq M_{\mathrm{P}} .
$$

The shear capacity at the end of the coupling beam supported by the web bolts is as follows:

$$
V=n_{1} N_{\mathrm{v}}^{b}=4 \times 112.5=450.0 \mathrm{kN} \geq V_{\mathrm{p}} .
$$

Details of connection of four modular prefabricated HCW prototypes (CR-40, CR-50, CR-60, and CR-70) are shown in Table 2.

4.3. Finite Element Model. The seismic behavior of the designed modular prefabricated HCW system is assessed through a pseudostatic analysis implemented with finite element software ABAQUS. The C3D8R element was used for the structure. This element has eight nodes and three degrees of freedoms per node. The mesh size is $50 \mathrm{~mm}$. The parts that were connected using high-strength bolts were defined as being in a contact relationship. The bolts were not 
TABLE 2: Details of connection.

\begin{tabular}{lcccc}
\hline $\begin{array}{l}\text { Model } \\
\text { name }\end{array}$ & $\begin{array}{c}\text { Steel grade } \\
\text { of bolt }\end{array}$ & Bolt diameter & $\begin{array}{c}\text { Bolt quantity on each flange } \\
\text { member (row } \times \text { column) }\end{array}$ & $\begin{array}{c}\text { Bolt quantity on each flange } \\
\text { member }(\text { row } \times \text { column })\end{array}$ \\
\hline CR-40 & Grade S10.9 & M16 & $4(2 \times 2)$ & $6(3 \times 2)$ \\
CR-50 & Grade S10.9 & M20 & $4(2 \times 2)$ & $6(3 \times 2)$ \\
CR-60 & Grade S10.9 & M24 & $4(2 \times 2)$ & $8(4 \times 2)$ \\
CR-70 & Grade S10.9 & M30 & $6(2 \times 3)$ & $15(5 \times 3)$ \\
\hline
\end{tabular}

built into the analysis model. The pretension of the highstrength bolts was simulated using the equivalent force method, and pretensions were applied on the cover plate [25]. A CR $=50 \%$ finite element model used in ABAQUS is shown in Figure 8. In addition, the nonlinear material behavior of steel was modeled using the kinematic hardening rule and Von Mises yield criteria and the tangent modulus after yielding $E_{\mathrm{t}}=0.01 E_{\mathrm{s}}$, where $E_{\mathrm{s}}$ is the modulus of elasticity, as shown in Figure 9. The constitutive model of concrete was based on the damaged plasticity model in ABAQUS. The models were subjected to lateral loads at all stories with an inverted triangular pattern for load distribution among the stories according to multiple point constraints. The loading history is shown in Figure 10. As seen from Figure 10, the incremental value was $\Delta_{\mathrm{y}}$ in each step, where $\Delta_{\mathrm{y}}$ is the yield displacement. Further, the out-plane translational DOF of each beam was constrained to consider the impact of lateral supports, secondary beams, and floors. The influences of initial imperfections and residual stress are neglected, and $P$ delta effects are considered in the hysteretic analysis.

4.4. Verification of Finite Element Model. In order to verify the reliability of the model, a 1/3-scale 5-story HCW specimen in the literature [26] is selected for simulation. Hysteretic curves and skeleton curves for both the test specimen and the relevant finite element model are shown in Figure 11. Overall, the hysteretic response demonstrates a good correlation between the numerical and the experimental results, except for the pinch effect. The analysis results of the model compared with the test are summarized in Table 3. The results show that both model and the test have similar yield load $P_{\mathrm{y}}$, yield displacement $\Delta_{\mathrm{y}}$, and ultimate load $P_{\mathrm{u}}$. The comparison between the finite element model and the test is carried out that the results of using ABAQUS for nonlinear analysis are available.

\section{Analysis of Results}

5.1. Hysteretic Curve. The shear force-displacement curves of the models are illustrated in Figure 12. The following conclusions can be drawn. (1) All the models possessed stable and expanding hysteretic loops. Further, the hysteretic loops of each model were plump; therefore, we can infer that the energy dissipation capacity of the modular prefabricated HCW is highly significant. (2) The CR- 40 model exhibited no deterioration in stiffness and load-carrying capacity when the interstory drift was $1 / 120$ the limit of interstory drift in JGJ32010. The ultimate failure of the structure was due to yielding of all the coupling beams and excessive displacement of the

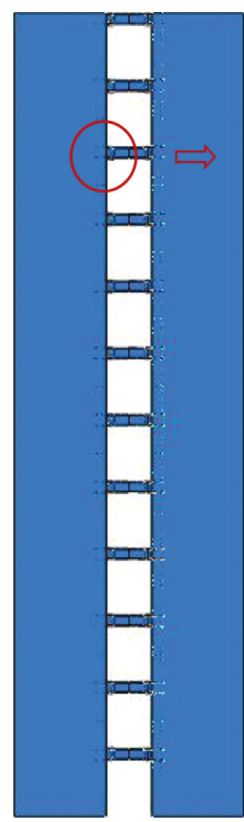

(a)

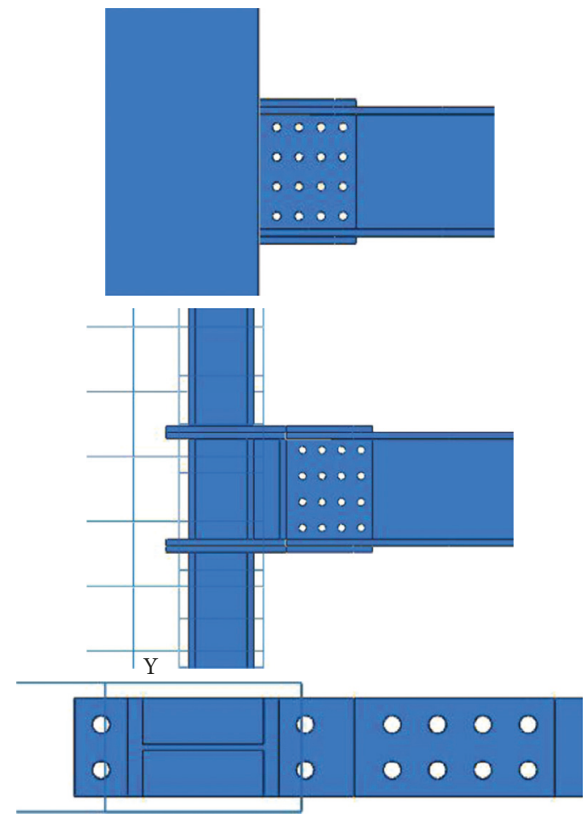

(b)
Figure 8: (a) FEA model. (b) Connection details of FEA model.

top of the structure. The CR-40 model exhibited small lateral stiffness. (3) The CR-50 and CR-60 models also exhibited high lateral stiffness, bearing strength, and ductility. The models were loaded up to $3 \Delta_{\mathrm{y}}$ before the interstory drift reached 1/ 120 of the story height. The structure adopted the ideal progressively plastic mechanism. (4) The yield displacement of CR-70 was small, and the stiffness and load-carrying capacity decreased significantly at the latter part of loading.

5.2. Load-Carrying Capacity. A model skeleton curve is presented in Figure 13. The value of the ultimate loadcarrying capacity of the models is presented in Table 4 . As shown in the skeleton curves, the model achieved a larger load-carrying capacity along with increasing $\mathrm{CR}$, as expected in CR-70. The load values of CR-50 and CR- 60 were $47 \%$ and $101 \%$ higher than CR-40, respectively. However, the load value of CR-70 was $91 \%$ higher than CR-40 and approximately $10 \%$ less than CR- 60 .

5.3. Stiffness Degradation. The stiffness of all the models could be calculated as follows:

$$
K=\frac{\left|P^{+}\right|+\left|P^{-}\right|}{\left|\Delta^{+}\right|+\left|\Delta^{-}\right|}
$$




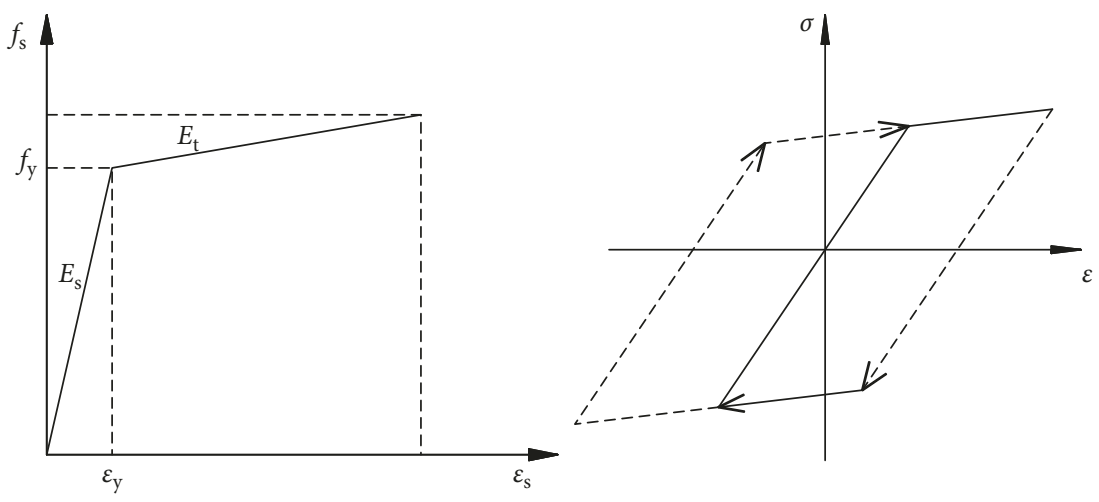

FIgURE 9: Bilinear kinematic hardening model.

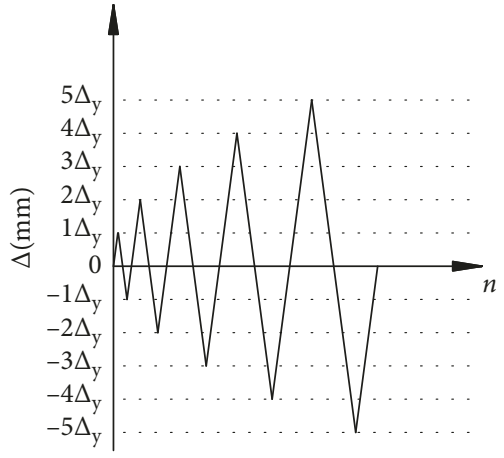

Figure 10: Loading history.

where $P^{+}$and $P^{-}$are the maximum lateral force in the positive and negative directions in the same hysteretic loop, respectively, and $\Delta^{+}$and $\Delta^{-}$are the maximum top-story displacement in the positive and negative directions in the same hysteretic loop of $P^{+}$and $P^{-}$, respectively.

The stiffness degradation could reflect the stiffness variation of the models during the loading cycles. Figure 14 shows the stiffness degradation curves of the models using equation (36). The curves indicate that the initial stiffness increases with increasing CR. The initial stiffness of CR-50, CR-60, and CR-70 was 48\%, 148\%, and 189\% higher than CR-40 (positive loading), respectively. This phenomenon is due to the better structural integrity of the models, thus leading to higher lateral stiffness. However, when the value of CR reached $70 \%$, the stiffness degradation was faster than those of other models at the later stage.

5.4. Ductility Capacity. The displacement ductility coefficient of all the models could be calculated as follows:

$$
\mu_{\mathrm{u}}=\frac{\Delta_{\mathrm{u}}}{\Delta_{\mathrm{y}}},
$$

where $\Delta u$ and $\Delta_{\mathrm{y}}$ are the ultimate displacement and yield displacement, respectively. The $\Delta_{\mathrm{y}}$ of each structure was determined based on the method shown in Figure 15. The top-story displacements, global drifts, and displacement ductility coefficients of the models are summarized in Table 5 , where $H$ is the height of the models.
The displacement ductility coefficient of the models was slightly lower with increasing CR. Except for CR-70, the displacement ductility coefficient of each model was greater than 3 , exhibiting good ductility.

5.5. Development of Plastic Hinge. The development of the plastic hinge is presented in Figure 16. To generate more visible results, four events are marked in each skeleton curve from the first to the last batch of the plastic hinge, as shown in Figure 17. This indicates that the first yielding in the coupling beams always occurs in the intermediate floor while the structure is still in the elastic state and that most coupling beams yield before primary structure damage; after the inelastic phase, the distribution of the plastic hinge is proper and reasonable, expect for CR-70. Thus, the displacement ductility coefficient is greater than 3 , and the requirement of ductility design is satisfied if the value of $\mathrm{CR}$ is below $60 \%$. This indicates considerable variations in the seismic performance of modular prefabricated HCW systems with different values of CR. As shown in Figure 17, when the plastic hinge appears at the bottom of the shear walls, smaller lateral deformations are required with increasing CR. However, if the plastic hinge appears at the coupling beams, a larger lateral deformation is required with increasing CR, thus resulting in difficulty of exploiting the plastic deformation of the coupling beams to dissipate the seismic energy when the CR value is equal to $70 \%$. This situation is not desirable in the performance-based design. In fact, it is the effect of the actual capacity of shear force redistribution among the coupling beams in modular prefabricated HCWs. The shear force distribution of the coupling beams tends to be nonuniform along with the increase in the CR, and the shear redistribution ability of the structure is insufficient.

5.6. Effect of Full-Bolt Connection on Joint Behavior. Figure 18 shows the stress and the deformation of the connection when the CR-50 finite element model failed, under the ultimate load $689 \mathrm{kN}$. Notably, the flitch plate and flanges had not yielded yet, but a slight slip occurred between the flitch plate and column base, so the stiffness of the connection is between hinged and fully rigid. 


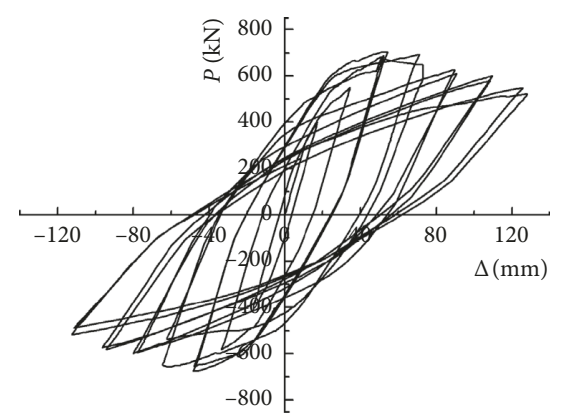

(a)

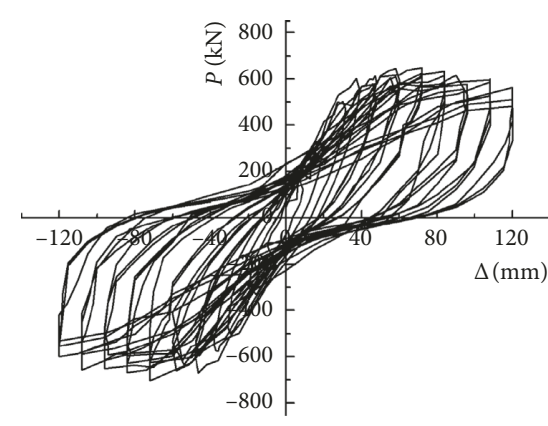

(b)

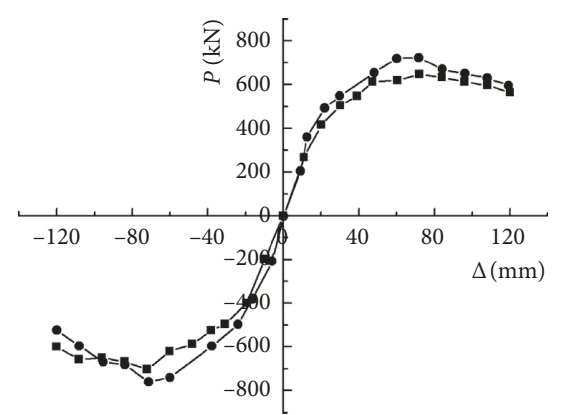

(c)

FIGURE 11: Comparison of finite element analysis curves with experimental ones. (a) Hysteretic curve in ABAQUS. (b) Hysteretic curve in test. (c) Skeleton curve comparison.

TABLE 3: Results comparison.

\begin{tabular}{|c|c|c|c|c|c|}
\hline & \multirow{2}{*}{ Loading direction } & \multicolumn{2}{|c|}{ Yield load point } & \multicolumn{2}{|c|}{ Ultimate load point } \\
\hline & & $P_{\mathrm{y}}(\mathrm{kN})$ & $\Delta_{\mathrm{y}}(\mathrm{mm})$ & $P_{\mathrm{u}}(\mathrm{kN})$ & $\Delta_{\mathrm{u}}(\mathrm{mm})$ \\
\hline \multirow{2}{*}{ ABAQUS } & Positive & 550 & 30.0 & 702 & 70.1 \\
\hline & Negative & -596 & -36.2 & -759 & -75.9 \\
\hline \multirow{2}{*}{ Test } & Positive & 535 & 36.5 & 647 & 72.0 \\
\hline & Negative & -515 & -38.0 & -701 & -72.0 \\
\hline
\end{tabular}

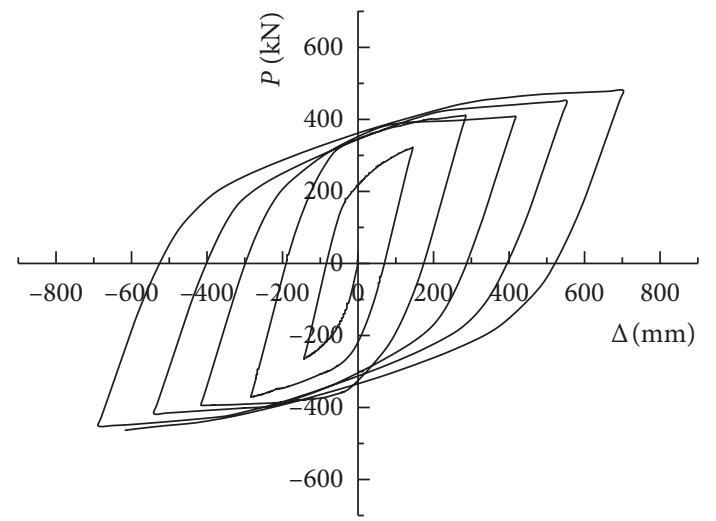

(a)

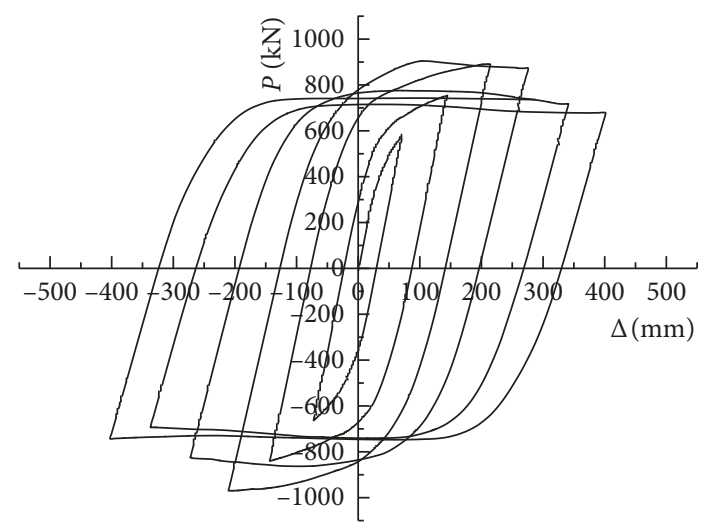

(c)

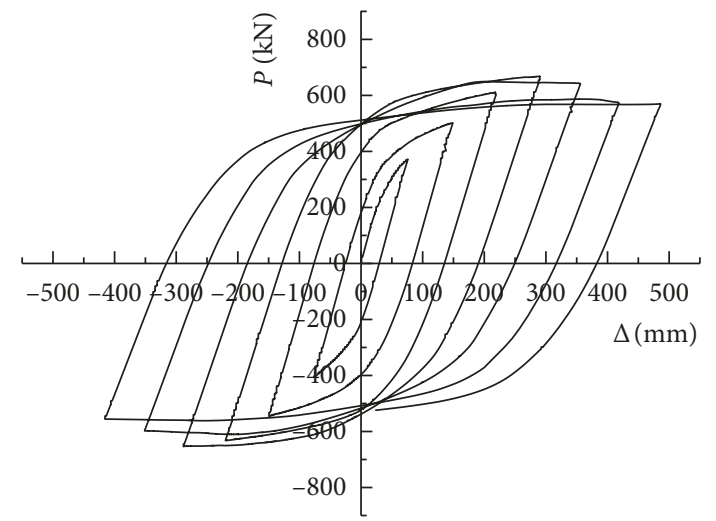

(b)

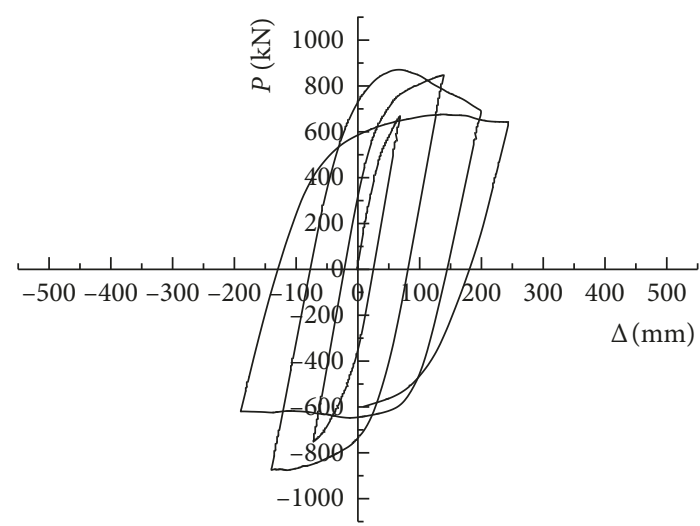

(d)

Figure 12: Force-displacement curves of the models. (a) CR-40. (b) CR-50. (c) CR-60. (d) CR-70. 


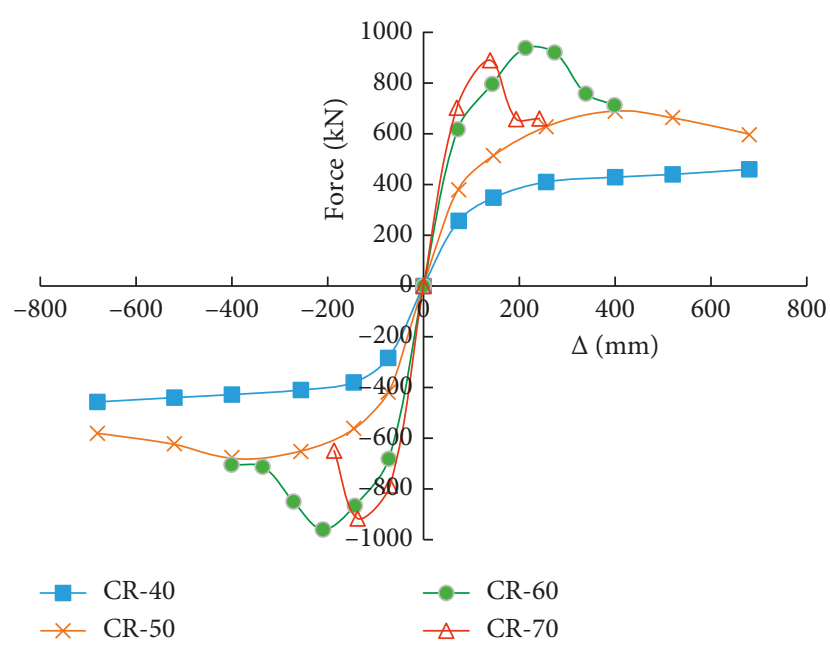

Figure 13: Skeleton curve of the models.

TABLE 4: Ultimate load-carrying capacity of the models.

\begin{tabular}{lcccc}
\hline Model name & CR-40 & CR-50 & CR-60 & CR-70 \\
\hline$P(\mathrm{kN})$ & 467 & 689 & 935 & 891 \\
\hline
\end{tabular}

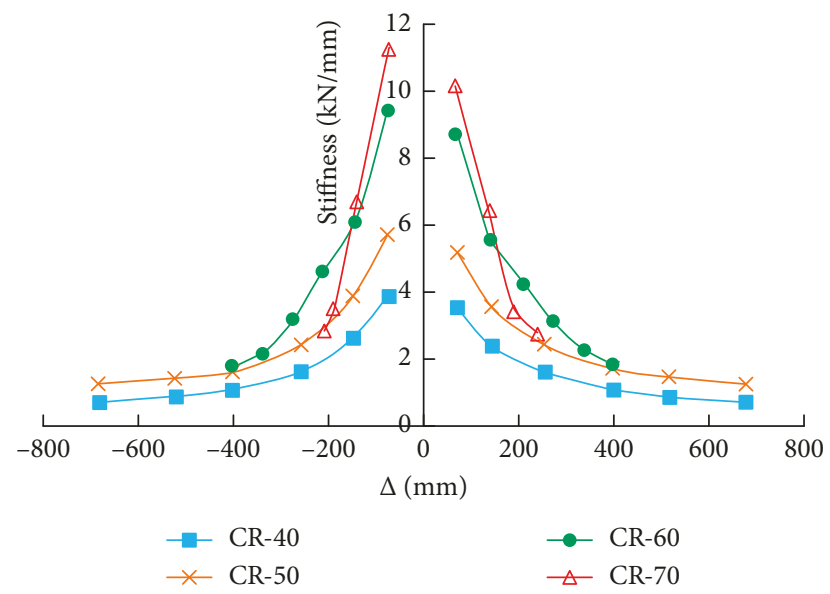

FIgURe 14: Stiffness degradation curves.

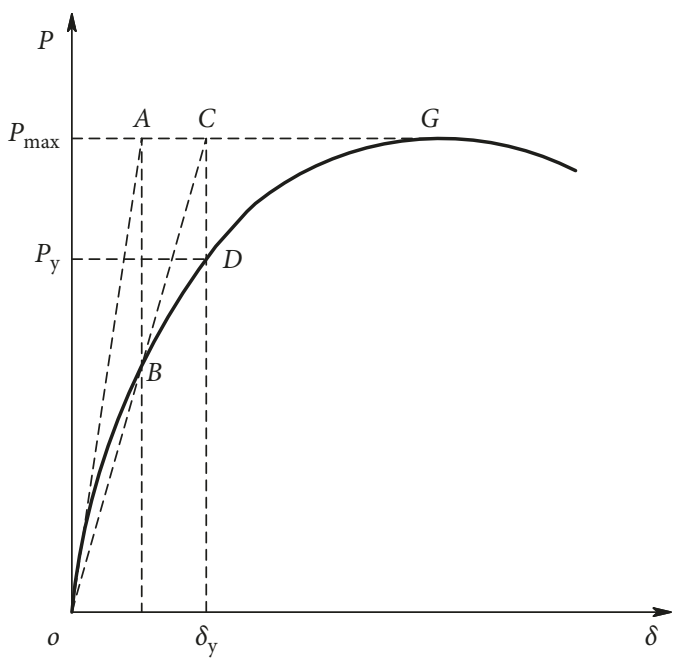

FIgURE 15: Method based on equivalent elastic-plastic yield.
TABLe 5: Displacement ductility coefficients of the models.

\begin{tabular}{lccccc}
\hline Model name & $\Delta_{\mathrm{y}}(\mathrm{mm})$ & $\Delta_{\mathrm{y}} / H$ & $\Delta u(\mathrm{~mm})$ & $\Delta u / H$ & $\mu$ \\
\hline CR-40 & 135 & $1 / 154$ & 546 & $1 / 58$ & 4.05 \\
CR-50 & 103 & $1 / 181$ & 397 & $1 / 84$ & 3.85 \\
CR-60 & 92 & $1 / 365$ & 289 & $1 / 116$ & 3.14 \\
CR-70 & 69 & $1 / 487$ & 152 & $1 / 221$ & 2.20 \\
\hline
\end{tabular}

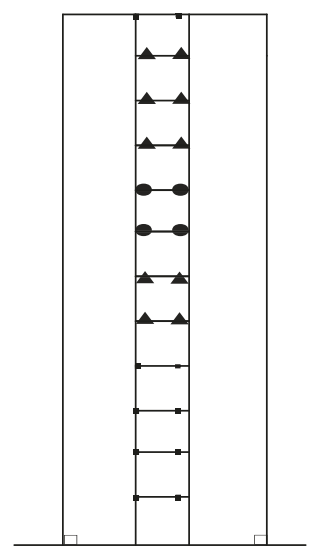

- First batch of plastic hinge - Second batch of plastic hinge - Third batch of plastic hinge 口 Fourth batch of plastic hinge

(a)

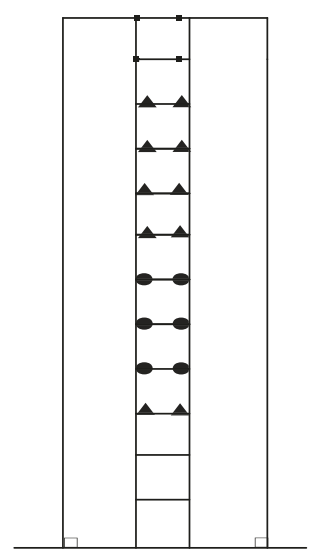

- First batch of plastic hinge

- Second batch of plastic hinge

- Third batch of plastic hinge

Fourth batch of plastic hinge

(c)

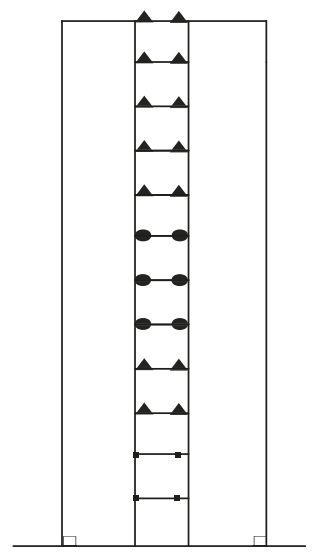

- First batch of plastic hinge - Second batch of plastic hinge - Third batch of plastic hinge 口 Fourth batch of plastic hinge

(b)

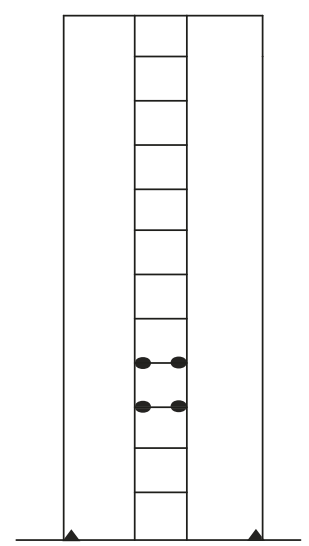

- First batch of plastic hinge

- Second batch of plastic hinge

- Third batch of plastic hinge

口 Fourth batch of plastic hinge

(d)
FIGURE 16: Development of plastic hinge. (a) CR-40. (b) CR-50. (c) CR-60. (d) CR-70.

\section{Advantages and Correctness of CR-Based Design}

The calculation of CR from FEM analysis is shown in Table 6, where $\mathrm{CR}=N L / M_{\mathrm{u}}$. The values of CR from FEM analysis and theoretical calculation are shown in Table 7 , where error $=\left(\mathrm{CR}_{\mathrm{T}}-\mathrm{CR}_{\mathrm{F}}\right) / \mathrm{CR}_{\mathrm{T}}$. These results indicate that the 


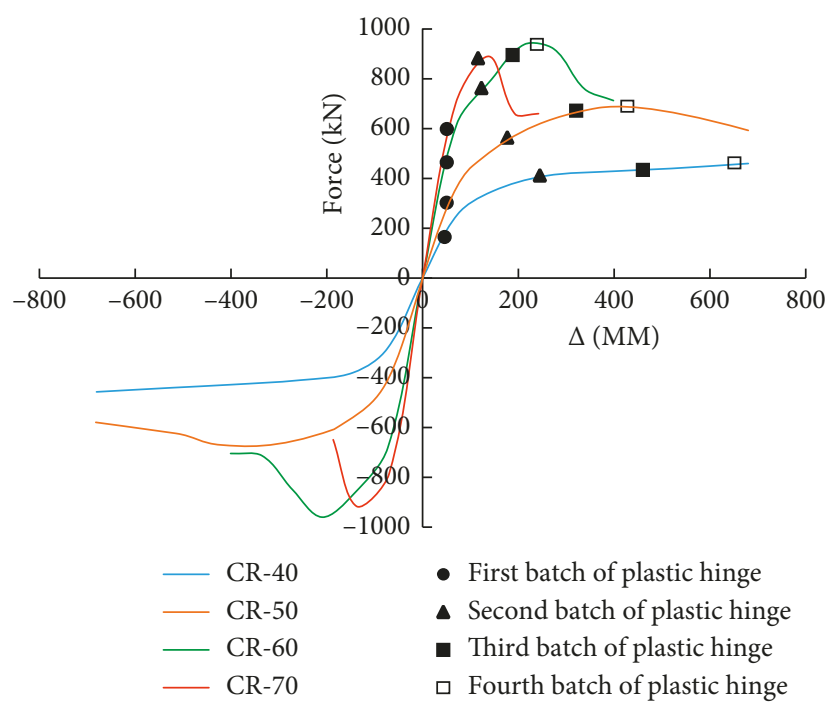

Figure 17: Development of plastic hinge.

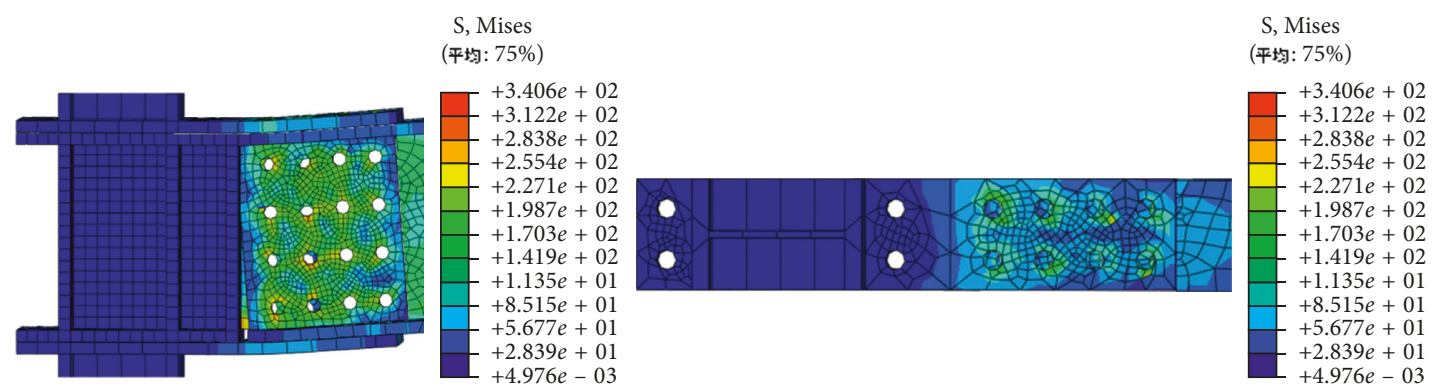

FIGURE 18: Mises stress distribution of full-bolt connection at ultimate displacement.

theoretical calculation has a certain feasibility and accuracy. For CR-40, CR-50, CR-60, and CR-70, the errors of the theoretical calculation of the structures relative to the FEM are $2.8 \%, 3.8 \%, 4.5 \%$, and $6.1 \%$, respectively. It is noteworthy that, as the value of CR increases, the error between the theoretical calculation and FEM analysis also increases gradually, because the theoretical design cannot consider the nonuniform distribution of shear force of the coupling beams. In addition, based on the comparison of the FEA results, the differences in seismic performance are presented (including hysteretic behavior, displacement ductility, and bearing capacity). A CR value of between $50 \%$ and $60 \%$ is better than those of other models. This study serves as a theoretical basis for the design of the initial cross section.

\section{Conclusions}

In this study, a modular prefabricated hybrid coupled shear wall system was presented. The estimation method of the CR was proposed according to the continuous connecting rod method, and a CR-based seismic design procedure was deduced based on the selected failure mode. Nonlinear hysteretic analysis was performed to verify the seismic performance of the modular prefabricated HCWs under
TABLE 6: Calculation of CR from FEM analysis.

\begin{tabular}{lcccc}
\hline Model name & CR-40 & CR-50 & CR-60 & CR-70 \\
\hline Ultimate load, $V_{\mathrm{u}}(\mathrm{kN})$ & 467 & 689 & 935 & 891 \\
Ultimate moment, $M_{\mathrm{u}}(\mathrm{kN} \cdot \mathrm{m})$ & 10449 & 15442 & 31416 & 29937 \\
Axial force of shear wall, $N(\mathrm{kN})$ & 1159 & 2120 & 5143 & 5619 \\
Axis length of shear wall, $L(\mathrm{~m})$ & 3.5 & 3.5 & 3.5 & 3.5 \\
Coupling ratio, CR $(\%)$ & 38.9 & 48.1 & 57.3 & 65.7 \\
\hline
\end{tabular}

TABLE 7: Value of CR.

\begin{tabular}{lcccc}
\hline Model name & $\begin{array}{c}\text { CR-40 } \\
(\%)\end{array}$ & $\begin{array}{c}\text { CR-50 } \\
(\%)\end{array}$ & $\begin{array}{c}\text { CR-60 } \\
(\%)\end{array}$ & $\begin{array}{c}\text { CR-70 } \\
(\%)\end{array}$ \\
\hline Theoretical & 40 & 50 & 60 & 70 \\
calculation (CRT) & & 48.1 & 57.3 & 65.7 \\
FEM analysis (CRF) & 38.9 & 3.8 & 4.5 & 6.1 \\
Error & 2.8 & &
\end{tabular}

inverted triangle horizontal forces in accordance with GB50011-2011. Finite element analyses were conducted using appropriate material stress-strain relations and failure criteria. The C3D8R element was used for the structure. The pretension of the high-strength bolts was simulated using the equivalent force method, and pretensions were applied 
on the cover plate. Parametric analyses were conducted to investigate the influences of different coupling ratios. The conclusions of this study are as follows:

(1) The hysteretic behavior of modular prefabricated HCWs was excellent, and the full-bolt-connected modular steel coupling beam could facilitate the rapid assembly of modules on site.

(2) Considerable variation occurred in the seismic performance of modular prefabricated HCW systems with different values of CRs. The basic requirements for ductile behavior and lateral stiffness were satisfied for CR values from $50 \%$ to $60 \%$.

(3) For higher CRs, the shear force distribution of the coupling beams tended to be nonuniform, and the shear redistribution ability of the structure was insufficient. This situation was not desirable in the performance-based design.

(4) The CR-based design method provided a theoretical basis for the seismic design of the initial cross section.

\section{Data Availability}

The data used to support the findings of this study are available from the corresponding author upon request.

\section{Conflicts of Interest}

The authors declare that they have no conflicts of interest.

\section{Acknowledgments}

The authors are grateful for the financial support from the National Natural Science Foundation of China (51808446), Shaanxi Natural Science Foundation (Grant nos. 2018JQ5184 and 2018JQ5073), and Yulin Natural Science Foundation (Grant no. 2016-29).

\section{References}

[1] A. Zona, H. Degée, G. Leoni, and A. Dall'Asta, "Ductile design of innovative steel and concrete hybrid coupled walls," Journal of Constructional Steel Research, vol. 117, pp. 204-213, 2016.

[2] J. Qian, W. Yong, Z. Zhao et al., "Experimental study on seismic behavior of SRC shear walls with high axial force ratio," Journal of Building Structures, vol. 29, no. 2, pp. 43-50, 2008.

[3] X. Liang, K. Ma, F. Li et al., "Experimental study on seismic behavior of SHSC structural walls," Journal of Building Structures, vol. 32, no. 6, pp. 68-75, 2011.

[4] F.-Y. Liao, L.-H. Han, and Z. Tao, "Performance of reinforced concrete shear walls with steel reinforced concrete boundary columns," Engineering Structures, vol. 44, no. 44, pp. 186-209, 2012.

[5] E. P. Popov and M. D. Engelhardt, "Seismic eccentrically braced frames," Journal of Constructional Steel Research, vol. 10, no. 1, pp. 321-354, 1993.

[6] L. Mastrandrea and V. Piluso, "Plastic design of eccentrically braced frames, II: failure mode control," Journal of Constructional Steel Research, vol. 65, no. 5, pp. 1015-1028, 2009.
[7] S. Yun, "Experimental study on hysteretic behavior of innovative hybrid coupled wall system with high coupling ratio," China Civil Engineering Journal, vol. 46, no. 1, pp. 52-60, 2013.

[8] A. Song, M. Su, and W. Li, "Experimental study on hysteretic behavior of full-scale shear-critical steel coupling beamcolumn connection in innovative bybrid coupled wall system," China Civil Engineering Journal, vol. 48, no. 7, pp. 71-81, 2015.

[9] Y. Wu, C. Dai, X. Yan et al., "Seismic performance of bolted end-plate steel coupling beams for coupled composite shear wall," China Civil Engineering Journal, vol. 12, pp. 39-48, 2014.

[10] X. Liu, A. Zhang, J. Ma, Y. Tan, and Y. Bai, "Design and model test of a modularized prefabricated steel frame structure with inclined braces," Advances in Materials Science and Engineering, vol. 2015, Article ID 291481, 12 pages, 2015.

[11] X. Liu, X. Cui, Z. Yang, and X. Zhan, "Analysis of the seismic performance of site-bolted beam to column connections in modularized prefabricated steel structures," Advances in Materials Science and Engineering, vol. 2017, Article ID 1932730, 18 pages, 2017.

[12] X. C. Liu, X. X. Zhan, S. H. Pu, A. L. Zhang, and L. Xu, "Seismic performance study on slipping bolted truss-tocolumn connections in modularized prefabricated steel structures," Engineering Structures, vol. 163, pp. 241-254, 2018.

[13] X. C. Liu, F. Y. Cui, X. X. Zhan, C. Yu, and Z. Q. Jiang, "Seismic performance of bolted connection of H-beam to HSS-column with web end-plate," Journal of Constructional Steel Research, vol. 156, pp. 167-181, 2019.

[14] N. Fanaie and H. S. Moghadam, "Experimental study of rigid connection of drilled beam to CFT column with external stiffeners," Journal of Constructional Steel Research, vol. 153, pp. 209-221, 2019.

[15] A. Moradi Garoosi, M. TahamouliRoudsari, and B. Hosseini Hashemi, "Experimental evaluation of rigid connection with reduced section and replaceable fuse," Structures, vol. 16, no. 16, pp. 390-404, 2018.

[16] R. Rahnavard, N. Siahpolo, M. Naghavi, and A. Hassanipour, "Analytical study of common rigid steel connections under the effect of heat," Advances in Civil Engineering, vol. 2014, Article ID 692323, 10 pages, 2014.

[17] E.-F. Deng, L. Zong, Y. Ding, X.-M. Dai, N. Lou, and Y. Chen, "Monotonic and cyclic response of bolted connections with welded cover plate for modular steel construction," Engineering Structures, vol. 167, pp. 407-419, 2018.

[18] S. Yun, H. Peng, and C. Ying, "Study on seismic performance of joint with modular prefabricated steel coupling beam-hybrid coupled wall," Earthquake Engineering and Engineering Vibration, vol. 3, pp. 45-51, 2018.

[19] W.-S. Park and H.-D. Yun, "Seismic behaviour and design of steel coupling beams in a hybrid coupled shear wall systems," Nuclear Engineering and Design, vol. 236, no. 23, pp. 24742484, 2006.

[20] R. Das, A. Zona, B. Vandoren, and H. Degée, "Optimizing the coupling ratio of seismic resistant HCW systems with shear links," Journal of Constructional Steel Research, vol. 147, pp. 393-407, 2018.

[21] GB50011-2010, Code for Seismic Design of Buildings, China Architecture\& Building Press, Beijing, China, 2010.

[22] JGJ99-2015, Technical Specification for Steel Structure of Tall Building, China Architecture\& Building Press, Beijing, China, 2015. 
[23] JGJ138-2016, Code for Design of Composite Structures, China Architecture\& Building Press, Beijing, China, 2016.

[24] GB50017-2003, Code for Design of Steel Structures, China Architecture\& Building Press, Beijing, China, 2003.

[25] X. C. Liu, S. H. Pu, A. L. Zhang et al., "Static and seismic experiment for bolted-welded joint in modularized prefabricated steel structure," Journal of Constructional Steel Research, vol. 115, pp. 417-433, 2015.

[26] Y. Shi, M. Su, and X. Mei, "Experimental study on seismic behavior of hybrid coupled wall system with steel boundary elements," Journal of Earthquake Engineering and Engineering Vibration, vol. 33, no. 3, pp. 133-139, 2013. 


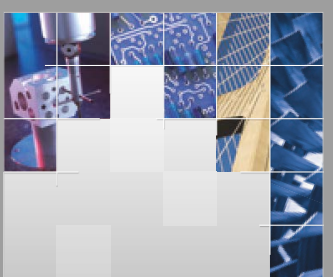

\section{Enfincering}
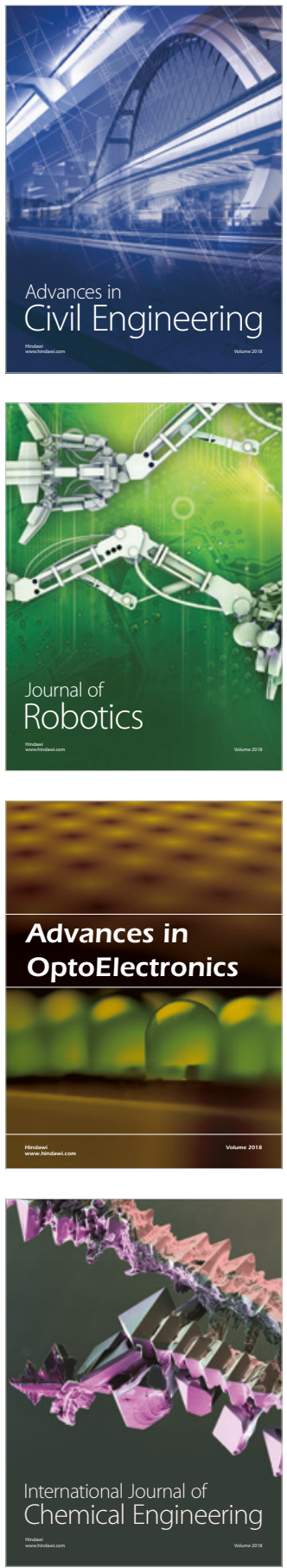

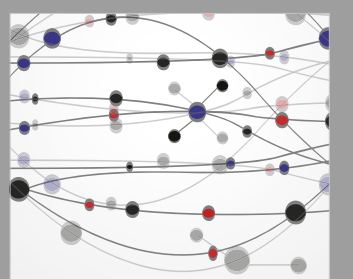

\section{Rotating \\ Machinery}

The Scientific World Journal

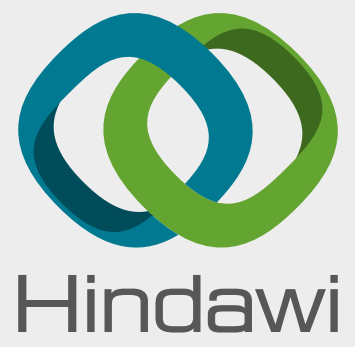

Submit your manuscripts at

www.hindawi.com
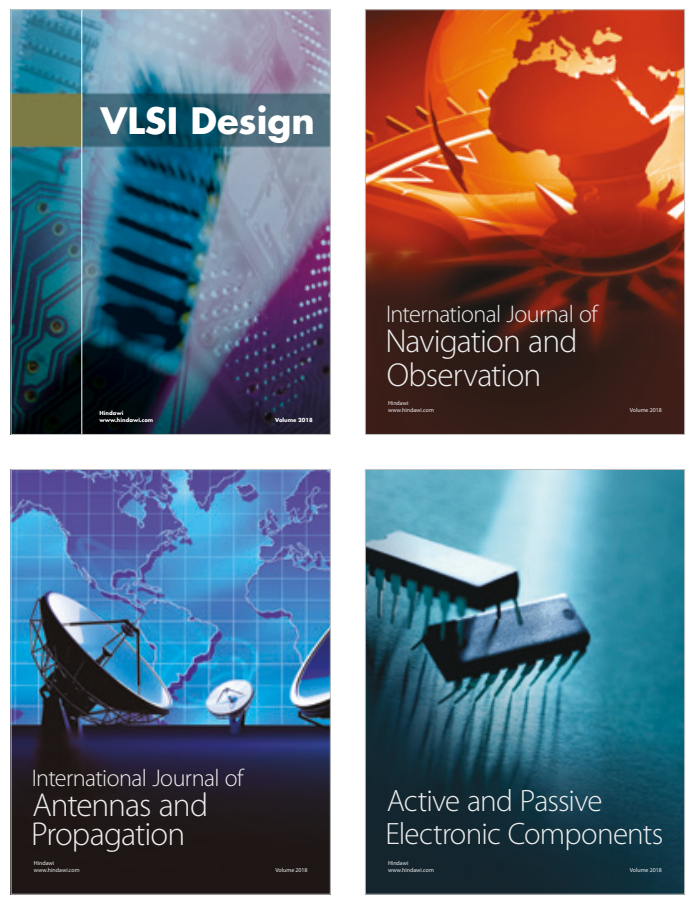
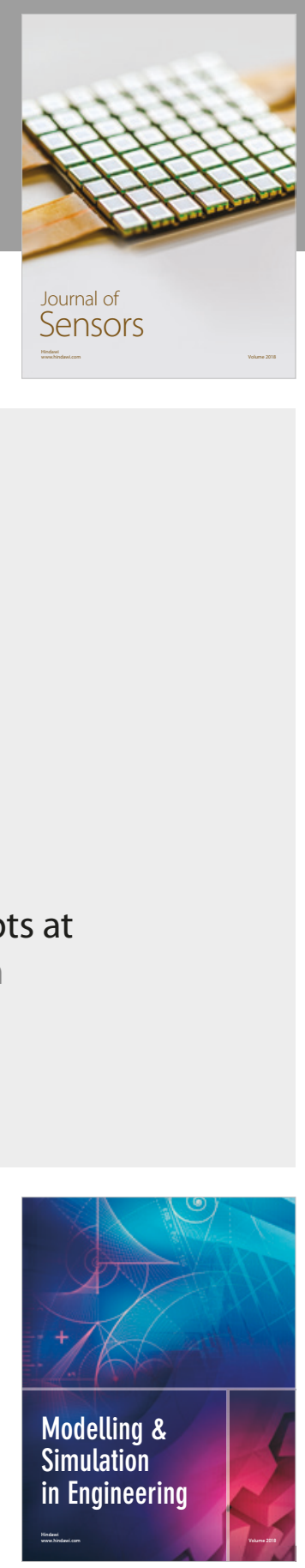

\section{Advances \\ Multimedia}
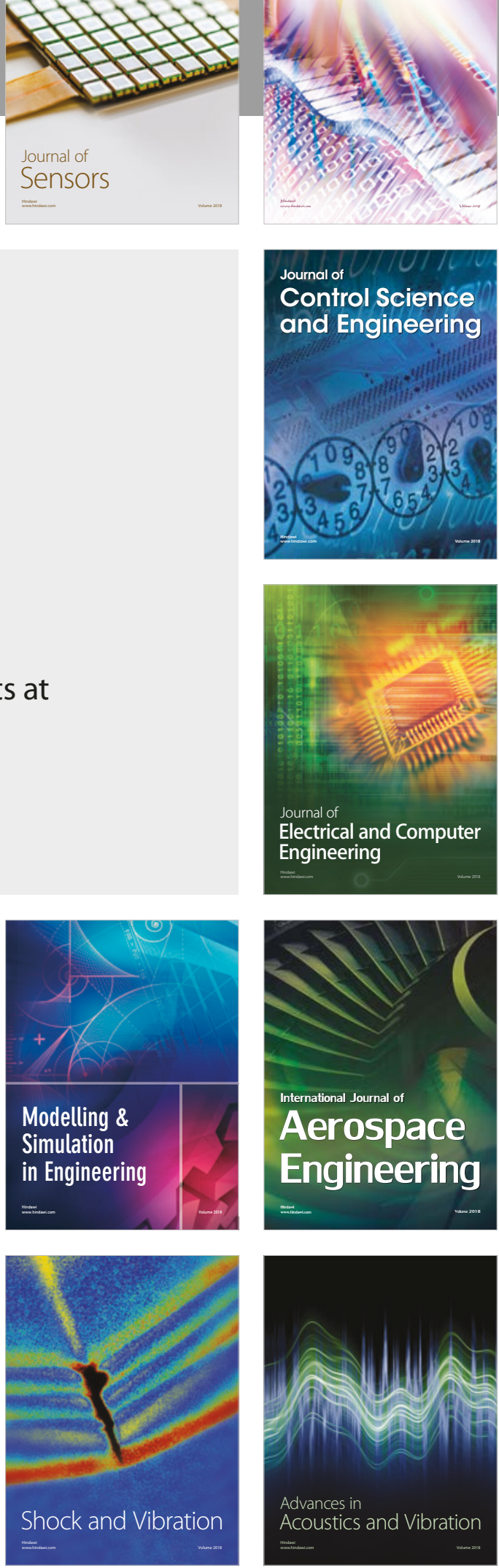